\title{
Helping and Volunteering across Cultures: Determinants of Prosocial Behavior
}

Arzu Aydinli

Tilburg University, the Netherlands, a.aydinli@uvt.nl

Michael Bender

Tilburg University, the Netherlands, m.bender@uvt.nl

Athanasios Chasiotis

Tilburg University, the Netherlands, A.Chasiotis@uvt.nl

Follow this and additional works at: https://scholarworks.gvsu.edu/orpc

Correspondence concerning this article should be addressed to Arzu Aydinli, School of Social and Behavioural Sciences, Tilburg University, P. O. Box 90153, Tilburg 5000 LE, The Netherlands. Phone: (+31)13 466 2526. E-mail: A.Aydinli@tilburguniversity.edu This research was supported in part by a grant from the Jacobs Foundation (grant reference number 2010-861) to the second author.

\section{Recommended Citation}

Aydinli, A., Bender, M., \& Chasiotis, A. (2013). Helping and Volunteering across Cultures: Determinants of Prosocial Behavior. Online Readings in Psychology and Culture, 5(3). https://doi.org/10.9707/2307-0919.1118 
Helping and Volunteering across Cultures: Determinants of Prosocial Behavior

\section{Abstract}

Why do people help others and what motivates them to engage in voluntary work? Are the psychological mechanisms that initiate prosocial behavior similar across cultures? In order to find answers for these questions, we give an overview of the prominent approaches to helping, and report findings of studies investigating informal spontaneous help and formal, planned forms of helping. A linchpin of our review is to go beyond a mere descriptive comparison of helping and volunteering across cultures, and to examine the pathways leading to helping and volunteering, which we argue can be considered universal across cultural contexts. Previous studies demonstrate cultural differences in the frequencies of helping and volunteering. Particularly when the prosocial act is not directed at close others, i.e., at outgroup members, differences between cultural samples are likely to emerge. In situations of spontaneous helping, helping is more frequent in rural and less affluent contexts than in urban and wealthier contexts. For long-term commitments of helping (i.e., volunteering) however, the reverse direction is found. Here, rates of volunteering are higher in more western and affluent countries.

We propose a model of helping that assumes different precursory mechanisms involved in these two forms of helping: spontaneous helping is an unconscious and implicit process activated by automatic affective components, whereas the decision and action of volunteering is a more conscious and explicit effort, initiated by elaborate considerations. We assume these two ways of initiating prosocial acting - implicit and explicit- to function similarly across different cultural groups. We conclude by highlighting conceptual, integrative avenues for a more systematic investigation of helping, and indicate methodological issues that need to be addressed in future research. In particular, we argue for the use of implicit measures in research of prosocial behavior, and present exemplary results for such an approach, which supports the proposed two-process model of prosocial behavior, and thus highlights the relevance for using both explicit and implicit measures in research on prosocial behavior.

\section{Creative Commons License} c)

This work is licensed under a Creative Commons Attribution-Noncommercial-No Derivative Works 3.0 License. 


\section{Aydinli et al.: Helping and Volunteering across Cultures}

\section{Introduction}

Prosocial behavior is a collective term covering all activities that are advantageous to other persons or the society in general (Pilliavin, Dovidio, Gaertner \& Clark, 1981). It can be divided into three categories, being a) altruism, b) helping, and c) cooperation. The focus of this paper lies on the category of helping since it can be considered the broadest and least restricted subgroup of prosocial acting. Helping activities do not have constraints with respect to the intention or outcome of the prosocial act. That means that having personal, even selfish reasons for helping can be considered - in contrast to altruism which requires the act to be exclusively motivated by other-serving goals. In that latter case, the positive outcomes for the recipient are sufficient to classify an action as helping. Cooperation requires positive outcomes for both parties, unlike altruism or helping.

On a daily basis, varieties of helping acts can be observed in all cultures and societies. But we know little about the extent to which mechanisms and manners related to helping are similar or different across cultures. Several fundamental questions emerge: Are such anteceding mechanisms similar or rather different across cultures? And what about helping frequencies: do they differ depending on cultural context? For instance, are people living in traditional cultural environments more or less helpful than people living in modern western societies? And if there are differences, how can they be explained? This paper will provide answers to these questions. To do so, we first introduce prominent theoretical approaches to prosocial behavior, define our target area, subsequently report relevant empirical findings, and conclude with an outlook on where future research could and should be going.

\section{Theoretical Approaches}

Approaches to explain prosocial behavior in general and helping in particular are numerous and span different disciplines (Eisenberg, Fabes, \& Spinrad, 2006). In this paper we limit ourselves to two approaches: first we introduce the evolutionary perspective that explains ultimate reasons of why helping occurs (i.e., functions of helping), and then highlight psychological approaches that focus on more proximate mechanisms of how prosocial behavior emerges.

\section{Evolutionary approaches to helping}

The evolutionary perspective on helping proposes that helping depends on genetic relatedness, age, and the reproductive value of the recipient (Burnstein, Crandall \& Kitayama, 1994). Known in the literature as kin selection, this form of helping contributes to the helpers' inclusive fitness, i.e., the sum of the individual fitness outcomes resulting from own procreation (Darwinian fitness) and the procreation of relatives with whom the individual shares genes (Hamilton, 1964). Another principle that is based on evolutionary considerations, but goes beyond helping within the boundaries of kinship, is known as reciprocal altruism. Here, helping is an evolutionary adaptive strategy when people share a 
social context that entails a high likelihood of future interactions, in which some kind of reciprocity therefore can be anticipated (Trivers, 1971; for more evolutionary considerations on prosocial behavior see also Barrett, Dunbar, \& Lycett, 2002; Chasiotis, 2011a).

\section{Psychological approaches to helping}

The functionality of the evolutionary concepts on helping is based on mostly nonconscious and ultimate cost-benefit calculations (degree of shared genetic information, likelihood of future interactions). Such a self-serving perspective of prosocial acts can be also recognized in the more proximate, psychological concepts that explain helping behavior. A prominent psychological approach identifies two broad categories of egoistic motives as the driving force for the initiation of helping:

First, based on their learning experiences, people may expect positive outcomes such as financial benefits, social recognition, or positive feelings about themselves from helping (e.g., Dunn, Aknin \& Norton, 2008; Schaller \& Cialdini, 1988; Smith, Keating \& Stotland, 1989).

Second, knowing another person is in need can create a negative emotional state of personal distress - which can possibly be relieved by the act of helping (or avoiding people in distress; Eisenberg \& Fabes, 1991; Fultz, Schaller, \& Cialdini, 1988; Lindsey, Yun \& Hill, 2007).

Furthermore, psychological approaches consider genuine empathic concern as an antecedent for helping: the empathy-altruism hypothesis (Batson \& Shaw, 1991; Batson, Ahmad, Lishner \& Tsang 2002) posits that the primary reason for helping is the identification with the person in need, which evokes empathic feelings, and eventually elicits altruistic motivation - which goes beyond the mere reduction of one's own personal distress. The maximization of rewards and minimization of costs is the key principle of another psychological explanation put forth by the social exchange theory (Foa \& Foa, 1975). Here people consciously weigh whether the gains of helping and the costs associated with not helping outweigh the costs associated with helping and the benefits of not helping. Social exchange theory posits that the behavioral alternative promising the best outcome will be chosen.

In summary, it seems that psychological approaches to helping focus on two distinct mechanisms: one that is based on conscious and cognitive considerations; and another one that is rooted in more implicit and affective experiences. Notably, both mechanisms are in line with the assumption that helping is a mean to attain positive end-states.

\section{Classification of helping}

One of the few psychological classifications of helping with an empirical basis is the taxonomy by Pearce and Amato (1980; see also McGuire, 1994). They proposed a categorization of helping activities after students rated the similarity of two helping behaviors that were presented together. Their results suggest that helping activities can be arranged along three dimensions: 


\section{Aydinli et al.: Helping and Volunteering across Cultures}

1. planned / formal help versus spontaneous / informal help,

2. emergency helping versus non-emergency (unserious) helping

3. direct helping / doing versus indirect helping / giving.

For the purpose of this review, we focus on the distinction between planned / formal help and spontaneous / informal help. First, we review studies focusing on informal and spontaneous helping, and then look at volunteering as the arguably most planned and formal form of helping.

\section{Spontaneous Helping Across Cultures}

So far, most of psychological research on spontaneous helping investigated how selfreported attitudes, values, traits, and skills are related to helping (Eisenberg et al., 2006; for a recent example see Caprara, Alessandri, \& Eisenberg, 2012). Studies highlighted for instance the importance of empathy (e.g., Penner, Fritzsche, Craiger \& Freifeld, 1995; Twenge, Baumeister, DeWall, Ciarocco \& Bartels, 2007), or agreeableness (e.g., Caprara, Allesandri, Di Giunta, Panerai \& Eisenberg, 2010; Graziano, Habashi, Sheese \& Tobin, 2007) for helping.

At the same time, however, results demonstrated that personal dispositions may become more or less important for predicting helping depending on situational determinants. For instance findings of Graziano et al. (2007) show that agreeableness was only predictive when the target of help was a stranger (but not when it was a friend or sibling), or when the seriousness of the situation was low (but not when it was an emergency situation). Apparently, when help is directed at close others, or when the situation requires an emergency intervention, inter-individual differences in agreeableness become unimportant - possibly because they are overruled by a strong habit or norm to help in such situations. Hence, the prevailing situation substantially co-determines to what extent specific predictors are effective in predicting helping.

This is in line with the general reasoning that integrates dispositional and situational factors in personological research in a person $x$ situation framework and seeks to explain behavior as a result of an interaction between the two (Mendoza-Denton, Ayduk, Mischel, Shoda, \& Testa, 2001; Mischel \& Shoda, 1995). Accordingly, mechanisms underlying helping could differ across cultures since culture can be considered a placeholder for contextual differences. It may thus be the case that helping is more or less likely to occur in one cultural context (or situation) than in others.

\section{National comparisons}

Helping was assumed to occur more frequently among collectivists than individualists, due to the belief that they would be generally more socially oriented. However, empirical studies on actual distributions are rare sightings; one of these few, and one of the more recent, by Levine, Norenzayan, and Philbrick (2001) concludes that 
"the virtual absence of systematic cross-cultural investigations of helping is a serious impediment to a richer understanding of how the personality of a place relates to helping behavior" (p.544).

Acknowledging this deficit, the present review sheds light on how diverse cultural environments and their specific characteristics relate to spontaneous helping.

Levine et al. (2001, Levine, 2003) observed helping activities in a field experiment across big cities in 23 different countries (e.g., Rio de Janeiro, Amsterdam, Shanghai, Tel Aviv, New York, and 18 others) and assessed how frequently strangers were being helped in three different non-emergency spontaneous helping situations requiring little effort (e. g. alerting a stranger who dropped a pen). Helping rates showed large variations between the 23 cities, being highest in Rio de Janeiro (Brazil, 93\%) and lowest in Kuala Lumpur (Malaysia, 40\%). The overall helping score emerged to be positively correlated with the cultural value orientation of simpatia, a proactive concern for others, including being friendly, polite, and helpful to strangers. These cultural norms are mainly found in Spanish and Latin American contexts (Díaz-Loving \& Draguns, 1999; Triandis, Marín, Lisansky, \& Betancourt, 1984).

Furthermore, it is striking that variables such as population size or pace of life measured as average walking speed in these cities- remained unrelated to helping. Instead, the economic productivity of a country was significantly negatively related to the overall helping rate. In other words, helping occurred less often in wealthier contexts.

Concordant with this finding are results by Miller, Bersoff, and Harwood (1990). They confronted participants with hypothetical helping scenarios, and additionally varied the seriousness of the helping situation (i.e., minor vs. moderately serious vs. life-threatening) and the relationship between the persons involved (i.e., parent-child vs. best friend vs. stranger). Descriptions were presented to Indian and US American adults and children who were asked to indicate how responsible and morally obligated they would feel to help in each scenario. As expected, Miller and colleagues found that feelings of responsibility and obligation to help increase when helping scenarios are more serious and when the relationship to the target of help is closer. However, this dependency on seriousness and relationship closeness was much more pronounced for US Americans than for Indians meaning that Indians generally felt more responsible and obligated to help than Americans who reacted more situation- and target-dependent.

These findings demonstrate two things: first the importance of both the situation and the target of helping for experiencing feelings of responsibility; and second that there are pronounced differences in levels of responsibility between the two cultural groups.

Taking the study by Miller and colleagues (1990) as well as Levine and colleagues (2001) into consideration, would we then expect people from more traditional, collectivistic, and economically poorer environments - such as the Brazilians or Indians - to be generally more inclined to help than people from more western, affluent, individualistic contexts? Based on the currently available research, it seems too early to give a clear answer to this question. However, we can get another step ahead in understanding how characteristics of 


\section{Aydinli et al.: Helping and Volunteering across Cultures}

the environment relate to an individual's inclination to help by looking at studies comparing helping in urban vs. rural environments.

\section{Urban vs. rural environments}

The importance of urbanization - accompanied by socioeconomic, socio-demographic, familial, and socio-cultural differences - for helping is a relatively well studied line of research. In 1975, Korte and Kerr observed that strangers were being helped more often in rural (small towns around Massachusetts) than urban environments (Boston). This finding was extended by House and Wolf (1978) who analyzed the refusal rates of survey participation in representative samples of the United States. Again, refusal rates were higher in large cities than in small towns. However, it is not clear how generalizable these findings are, since the reported urban-rural differences were found within the USA, a context referred to as prototypically western and individualistic.

To examine whether similar urban-rural differences also occur in more traditional, and collectivistic contexts, Korte and Ayvalioglu (1981) examined helping within Turkey. They compared helpfulness towards a stranger in big cities, small towns, and squatter settlements. The squatter settlements of the big cities are particularly interesting to better understand the nature of the observed differences, as families with a low socio-economic status that migrated from rural areas were living there. Again, strangers were less often helped in the big cities than in the small towns and in the squatter settlements. Interestingly, no differences in helping between small towns and squatter settlements of the big cities emerged. Moreover, helping rates in the suburbs were found to be lowest. In accordance with Levine et al. (2001), these findings also point to the importance of economic factors. Moreover, finding no differences between the squatter settlements and the small towns indicates that it is not the situational specifics of the current urban environment alone.

After showing that differences in spontaneous helping between urban vs. rural environments basically correspond with what was found by Levine et al. (2001) on the level of cross-national comparisons, can we now conclude that spontaneous helping is more likely to occur in less developed, poorer contexts? Can we assume that people living in traditional collectivistic societies are more concerned with other peoples' welfare and thus will be more likely to help than those in modern western societies?

A study by Fjneman, Willemsen, and Poortinga (1996) conducted in Hong Kong, Greece, Turkey, the Netherlands, and the United States challenges this reasoning. Other than just focusing on whether help is given or not, this study takes another aspect into consideration: the expectation to receive help. Results portray that the pattern of readiness to provide help and expectations to receive help from ten different target persons and their ratios were found to be highly similar across all cultural contexts. Moreover, in all cultural contexts, differences between social categories were largely explained by ratings of emotional closeness. From emotionally closer targets, individuals reported both to expect more support, and to be more willing to provide support. In line with evolutionary principles of reciprocity in stable environments, emotionally close others (as opposed to strangers) 
warrant investment as it is likely that the relationship will remain stable over time for them to reciprocate. Fjneman and colleagues (1996) further find clear support for kinship altruism, with helping more likely to be performed when it benefits kin or close others. Overall, findings indicate that the ultimate functionality of acting prosocial, namely the reciprocity and kinship effect, is invariant across cultures.

Other studies (Georgas, Berry, van de Vijver, Kagitcibasi, \& Poortinga, 2006) corroborate this notion by finding that emotional closeness towards relatives is highly similar across cultures indicating that differences in helping should remain small when help is directed at close others, that is, at in-group members. However, when target persons are less close, i.e., out-group members, we expect more variance in the form of interindividual and inter-cultural differences in helping. We will present further evidence for this presumption in the next section.

\section{Helping out-group members vs. helping in-group members}

Indiscriminate helping is rare. We already mentioned that the target of helping substantially influences helping (e.g., Miller et al, 1990; Graziano et al., 2007). How perspectives on helping can change when accounting for the target of help is nicely demonstrated by Amato (1993). Similar to Korte and colleagues, Amato was interested in examining urbanrural differences on helping. However, he did not investigate the help directed at strangers, but help directed at close others. In total, 13,017 American individuals were asked to indicate whether they have given various types of help to family members, relatives, and friends over the past month. Unlike previous findings (e.g., House \& Wolf, 1978; Korte \& Kerr, 1975), this time results did not display urban-rural differences in helping. Apparently, when help is directed at family members, relatives and friends (as opposed to strangers) effects of urbanization on helping remain relatively small.

Again, this indicates that evolutionary considerations of helping apply. When helping is directed at close others, it may be based on kinship altruism that represents an internalized mechanism of survival and reproduction and might then explain why differences in helping between societies - and also between individuals (see Graziano et al., 2007) - are relatively small, or even not existing. Instead, differences seem to be particularly visible when help is directed at out-group members (i.e., strangers). While this provides us with an avenue to understand differences in low-effort spontaneous helping behavior, we next turn to high-effort, long-term and planned helping. Notably, the main focus of the present review will lie on volunteering, so that informal forms of planned and high-effort helping that are mostly directed at known others will only be considered marginally. 


\section{Planned Formal Helping: Volunteering Across Cultures}

Volunteering is defined as a long-term, planned, and non-obligatory form of helping. Unlike supporting family members, friends, neighbors, or close others, volunteering takes place in a formal, organizational context (Penner, 2002). On Pearce and Amato's (1980) dimension of spontaneous vs. planned / formal helping, volunteering represents one endpoint as the most planned and formal form of helping.

Even though benefits of volunteering for both the volunteer and the society are widely acknowledged (e.g., Atkins, Hart \& Donnelly, 2005; Cemalcilar, 2009), interest among psychologists in studying volunteering emerged relatively late - only within the past 20 years. Psychological research on antecedents of volunteering mainly concentrates on two theoretical approaches: the dispositional and the motivational approach to volunteering.

a) Focusing on dispositions, the prosocial personality model by Penner (2002) should be mentioned. This model proposes that other-oriented empathy and helpfulness are the most important predictors for volunteerism.

b) The second approach, the volunteer process model by Omoto and Snyder (1995) assumes that self-attributed motivational underpinnings predict volunteering. Studies found support for both approaches.

For instance, Penner and Finkelstein (1998) and later Penner (2002) showed that higher levels of a self-reported prosocial disposition (i.e., other-oriented empathy and helpfulness) were positively related to the amount of time spent on volunteering and the duration of the voluntary service.

On the other hand, Omoto and Snyder (1995) showed that a prosocial disposition predicts satisfaction with the volunteering experience, but fails to predict duration of volunteering. For the duration of volunteering, they identified a set of different motivations to be predictive. In their view, no uniform personality trait (such as a prosocial personality) or motivation exists that leads to volunteering. Instead, they noted that different volunteers perform their voluntary service for different reasons. Accordingly, Omoto and Snyder defined five different motivations that lead to volunteering. Later, in 1998, Clary and colleagues extended this to six motivations: values, understanding, protection, enhancement, career and social motivations. Taken together, both approaches clarify that individual dispositions and motivations substantially contribute to the explanation of volunteering and its sustainability.

However, the question we are particularly interested in is whether these characteristics function equally across cultural contexts. Similar to research on spontaneous helping, studies on the role of cultural context for volunteering are few in number. Comparisons between countries typically attempt to explain differing rates of volunteering by investigating the societal role of demographic or socioeconomic indicators (for a review see Wilson, 2000). Examining whether pathways leading to volunteering are affected by culture is still a relatively unexplored research area. Hence, we will approach 
this question indirectly by first reviewing cross-country comparisons of volunteering rates, and then highlight the role of group membership for volunteering.

\section{National comparisons}

One of the first studies investigating different rates of volunteering in different countries is the study by Curtis in 1971. Based on datasets from national surveys, he compared membership rates in voluntary associations in the United States of America, Canada, Great Britain, Western Germany, Italy, and Mexico. Membership rates were higher for Americans and Canadians than for citizens of the other four nations. Roughly 20 years later, Curtis, Grabb, and Baer (1992) investigated World Value Survey data (1981 to 1983) and compared the membership rates of 15 countries after controlling for sex, age, educational level, employment status, marital status, and community size. Again, USAmericans turned out to be leading by showing significantly higher membership rates than twelve out of fourteen countries.

Similar results were also found after analyzing World Value Survey data sets of 33 democratic countries from 1991 to 1993 (Curtis, Baer, \& Grabb, 2001). Findings suggest that cross national variance in association involvement is a function of economic development, religious composition, democracy history, and type of prevailing policy in the different nations. Rates of voluntary memberships and activities were typically high in countries with high levels of economic development, that are predominantly Christian (particularly protestant), that hold a prolonged democratic history, and that present a social democratic or liberal democratic political system.

Consistent interpretations can be derived from the meta-analysis done by Allik and Realo (2004). Here, associations between socio-cultural value orientation (i.e., countrylevel individualism-collectivism scores) and social capital - defined as the aggregate of social connectedness, civic engagement and generalized trust (Putnam, 1995; 2000) within the United States and across 42 nations were examined. Results show that social capital increased with higher levels of individualism. Similarly, Kemmelmeier, Jambor, and Leitner (2006) found charitable giving and volunteering to be higher in individualist than in collectivist states.

High scores on individualism in turn are typically found in countries with higher economic productivity that have a long lasting background of Christianity and democracy. What does this tell us? Overall, the cross national comparisons of volunteering demonstrate that the economic condition of a country is a key variable. Different from spontaneous helping, which was found to be more frequent in poorer countries (Levine et al., 2001), formal, long-term prosocial activities seem to be more prevalent in wealthier contexts (Allik \& Realo, 2004, Kemmelmeier et al., 2006).

\section{In-group vs. out-group volunteering}

We know from research on spontaneous helping that group membership of the target person is of substantial relevance (for a review see Stürmer \& Snyder, 2010). Several studies investigated in-group vs. out-group volunteering from a psychological perspective. 


\section{Aydinli et al.: Helping and Volunteering across Cultures}

One aspect that benefits in-group vs. out-group members is the helpers' form of identification. Simon, Stürmer, and Steffens (2000) investigated the differential effects of individual vs. collective identification on participants' self reported willingness to volunteer for in-group vs. out-group members. Here, individual identification meant that individuals defined and understood their self as unique and individual beings, whereas collective identification meant that individuals defined and understood their self as part of a bigger group. The findings of Simon and colleagues portray that in-group volunteering was facilitated by collective identification, whereas out-group volunteering was facilitated through individual identification, but inhibited by collective identification. However, it has to be noted, that their results are based on self reported scores of willingness to volunteer.

In a more recent study, Stürmer and Simon (2004) applied a longitudinal design with real life volunteering as dependent variable and tested the effect of collective identification on volunteering. Results of this panel study confirmed the hypothesis that higher levels of collective identification facilitate participation in social movements that benefit in-group members.

These results are particularly interesting since the form of identification probably represents a variable that shows large cross-cultural variation. We can presume that persons considering themselves as individual and socially more independent beings are more likely to be found in prototypically western, and affluent socio-cultural contexts. In turn, in more traditional, economically less developed interdependent socio-cultural contexts persons should more strongly perceive themselves as elements of bigger communities. Based on this assumption, we can expect in-group volunteering to be more frequent in interdependent contexts, whereas out-group volunteering should be more common in independent contexts. Since volunteering is a service largely benefiting unknown others (out-group members), our assumption receives some support from the observation that volunteering rates were typically higher in affluent and western communities.

A possible explanation for this can be derived from Triandis' (1995) argument that the distinction between in-group vs. out-group members is more strongly pronounced in collectivistic contexts, which might represent a consequence of a strong collective identification. In more individualistic contexts however, an individual - or universal identification might lead to less or even no consideration of group status, which in turn facilitates an appreciation of group independent, thus universal, helping (McFarland, Webb \& Brown, 2012).

In another set of studies, Stürmer and colleagues went beyond solely comparing differences of volunteering frequencies, and addressed the question whether in-group vs. out-group volunteering is initiated by the same mechanisms by examining motivational processes of in-group and out-group helping and volunteering (e.g., Siem \& Stürmer, in press; Stürmer, Snyder \& Omoto, 2005; Stürmer, Snyder, Kropp, \& Siem, 2006). Results of all studies show a pattern of in-group volunteering being initiated through empathic feelings, and out-group volunteering being initiated through more rational concerns such as considerations of interpersonal attraction. It seems that particularly out-group helping and out-group volunteering are based on rational anticipations of future interactions with 
the help recipient. The authors assume that high interpersonal attraction makes future interactions more likely. A high possibility of interaction also increases the probability of reciprocity in the future, and thus leads to higher volunteering. This means that long-term helping, also including repeated informal assistance, which requires much effort and commitment seems to be motivated though more cognition-based processed that serve the ultimate mechanism of reciprocal altruism. Whether or not reciprocity might be at the horizon should even have a stronger influence when the service is directed at out-group members. In turn, when long-term commitments of helping characterized by high effort benefit close others or in-group members, kinship altruism, which may be initiated by empathic reactions, could provide an explanation for helping. Notably both mechanisms of helping have in common that they direct individuals towards behaviors that are adaptive in their specific circumstances, although they are initiated by distinct psychological processes.

Against this background, it is also not surprising that inter-individual and inter-cultural variations in helping are generally small when help is directed at close others (e.g., Amato, 1993; Fjneman et al., 1996; Graziano et al., 2007; Miller et al., 1990). Helping close others might represent an adaptive strategy for most individuals and across cultural contexts. In contrast, the adaptive value of helping out-group members might strongly depend on societal and cultural structures, and eventually lead to high cross cultural variation.

\section{The Way Forward}

The studies we summarized so far underline that differences in helping across regions, communities, or nations are not uniform. But we have teased out systematic variations: Whether helping is more or less likely to occur in a particular context strongly depends on the type of helping and the target of helping. The findings suggest that providing spontaneous and low-effort aid to a stranger is more frequent in traditional, less affluent and rural areas than in modern, affluent and urban environments, whereas the opposite is the case for planned and long-term helping directed at out-group members, namely volunteering. Yet, there is the question of where differences in spontaneous helping and volunteering across regions come from.

Drawing on evolutionary considerations, it may well be the case that such differences in helping and volunteering may be the result of psychological adaptations to different socio-economical conditions, particularly as a result of experiences during ontogeny as a formative period for adult differences (Chasiotis, 2011a, 2011b, see also Bender \& Chasiotis, 2011; Chasiotis, Bender, \& Hofer, in press).

\section{Understanding cultural differences}

In past research, regional or national differences in helping and volunteering are mostly attributed to variations in community-level variables, such as socio-cultural value orientation (e.g., individualism vs. collectivism), socio-demographic and socio-economic features, or political characteristics. Although these variables strongly relate to helping 


\section{Aydinli et al.: Helping and Volunteering across Cultures}

tendencies, they hardly provide answers to why these differences occur. We suggest that important lessons can be learned if variations in the proximal environment of individuals that arise from such community-level determinants are considered. It is important to conceptually differentiate a person's ontogenetic context from the socio-economic context (which includes the community-level determinants).

The model by Bronfenbrenner (1979) clarifies that the higher order context may filtrate through to the specific ontogenetic circumstances in which a child grows up. More proximal variables that are influenced by country level features include the familial structure (e.g., number of siblings), or the physical distance to family members, available social networks, or socialization practices transmitting patterns of social behavior.

In line with this view is Kagitcibasi's research (1997) that focuses on an individuals' direct environment in an attempt to explain cultural differences. Based on her argumentation, the socioeconomic, socio-demographic and socio-cultural conditions of a community promote different strategies and forms of living. Hence, individuals adapt to different conditions of a community. For instance, in more traditional and poor societies with little or no social security, maintaining close relationships to relatives is more adaptive and desirable than in western and affluent societies, because kin, particularly offspring, provides a security net for old age or during emergencies (Kagitcibasi, 1997, 2007). In such conditions, intergenerational interdependence, as well as values of obedience and respect are fostered, which can be related to the high proximity of family members.

The emerging notion is that the interplay between ontogenetic conditions and resulting psychological adaptations offers an avenue to understand cultural differences between contexts that differ in higher order socio-economic conditions (Chasiotis, 2011b). In more industrialized contexts in turn, societal institutions may provide the needed structures that substitute personalized intergenerational contract through more abstract and depersonalized bonds with the society.

\section{The two processes model of helping: The effect of culture}

The findings for spontaneous helping and volunteering indicate that different processes are involved in these two forms of prosocial behavior. We presume that low-effort spontaneous helping is an implicit and unconscious act that is initiated by affective components, whereas high-effort and long-term prosocial commitments are rather cognition based and driven by conscious values, religious beliefs, and norms or elaborate and foresighted considerations of future reciprocity. Particularly when this cost-intensive form of helping is directed at those who are perceived as out-group members, cost-benefit calculations on whether future reciprocity is likely to be experienced or not should be more salient.

\section{Low-effort spontaneous help}

Differences between cultural groups or individuals in low-effort spontaneous helping (e.g., picking up dropped magazines, holding the door for someone, etc.) are generally more pronounced when help is directed at out-group members (strangers). When this form of 
help is given to in-group members, in the reviewed studies (e.g., Amato, 1993; Fjneman et al., 1996; Graziano et al., 2007) no significant cross-cultural or inter-individual differences could be shown. The process of giving spontaneous aid to a known other should therefore be an easy and almost automatic response, particularly when kin is involved. Helping in the form of "being polite" or "doing a small favor" is likely to constitute an essential element of social interactions in most communities. Thus, we expect that norms and patterns of how to interact with close others in situations requiring spontaneous intervention are largely similar across cultures. This also matches to predictions derived from kin selection: helping kin, or more generally close others is an adaptive strategy to survive across different cultural communities. This similarity is likely to come in the form of a ceiling effect that overrules the effect of other variables. The "habit" to provide assistance to close others might be so strongly anchored that differences become very unlikely. Particularly since the amount of effort required for this form of helping is often very small, the threshold for engaging in this form of helping should be very low.

As a consequence of the low costs for spontaneous helping, conscious anticipations of future reciprocity should be less relevant than for more cost-intensive forms of helping. Instead, spontaneous help should proceed in a more automatic and unconscious manner. It should more strongly relate to affective experiences such as the feeling of empathy, or internalized and societal norms of helping.

This also explains why strangers were more often helped in more traditional communities than in western environments. In a more traditional and rural area, being a stranger possibly has different implications than being a stranger in a modern, and mostly multicultural society. In small and more traditional communities were people typically know each other, strangers are rare and thus more likely to stand out from the crowd. Accordingly, their distinctiveness is much higher in a rural society than in a modern society that is entirely composed of people that do not know each other, i.e., strangers.

Hence, also social norms that determine how to treat a stranger - e.g. hospitality or simpatia (see Levine et al., 2001) - should come more to the foreground in communities where strangers are more distinct. Moreover, building on Kagitcibasi's $(1997,2007)$ perspective, different socio-cultural environments are likely to result in different psychosocial adaptations. For instance, being agreeable is more emphasized in child rearing in traditional and interdependent contexts - because it is more adaptive.

Agreeableness in turn has shown to be positively related to intentions of helping strangers (Graziano et al., 2007) and could thus provide one possible explanation for cross-national differences. Further examples of affective components that might be influenced by the socio-cultural context could be feelings of empathic concern (e.g. Twenge et al. 2007) or moral responsibility (e.g., Miller et al., 1990). An overview of the processes involved in spontaneous helping is given in Figure 1.

\section{Volunteering: High-effort, formal and planned help}

Volunteering is more common in affluent and western societies than in traditional and poor societies. In line with this, Simon et al. (2000) and Stürmer and Simon (2004) observe that 


\section{SPONTANEOUS HELPING: UNCONSCIOUS AFFECT-BASED PATHWAYS \\ Low amount of effort/costs \\ Low relevance of reciprocity/trust \\ Low threshold to provide help}
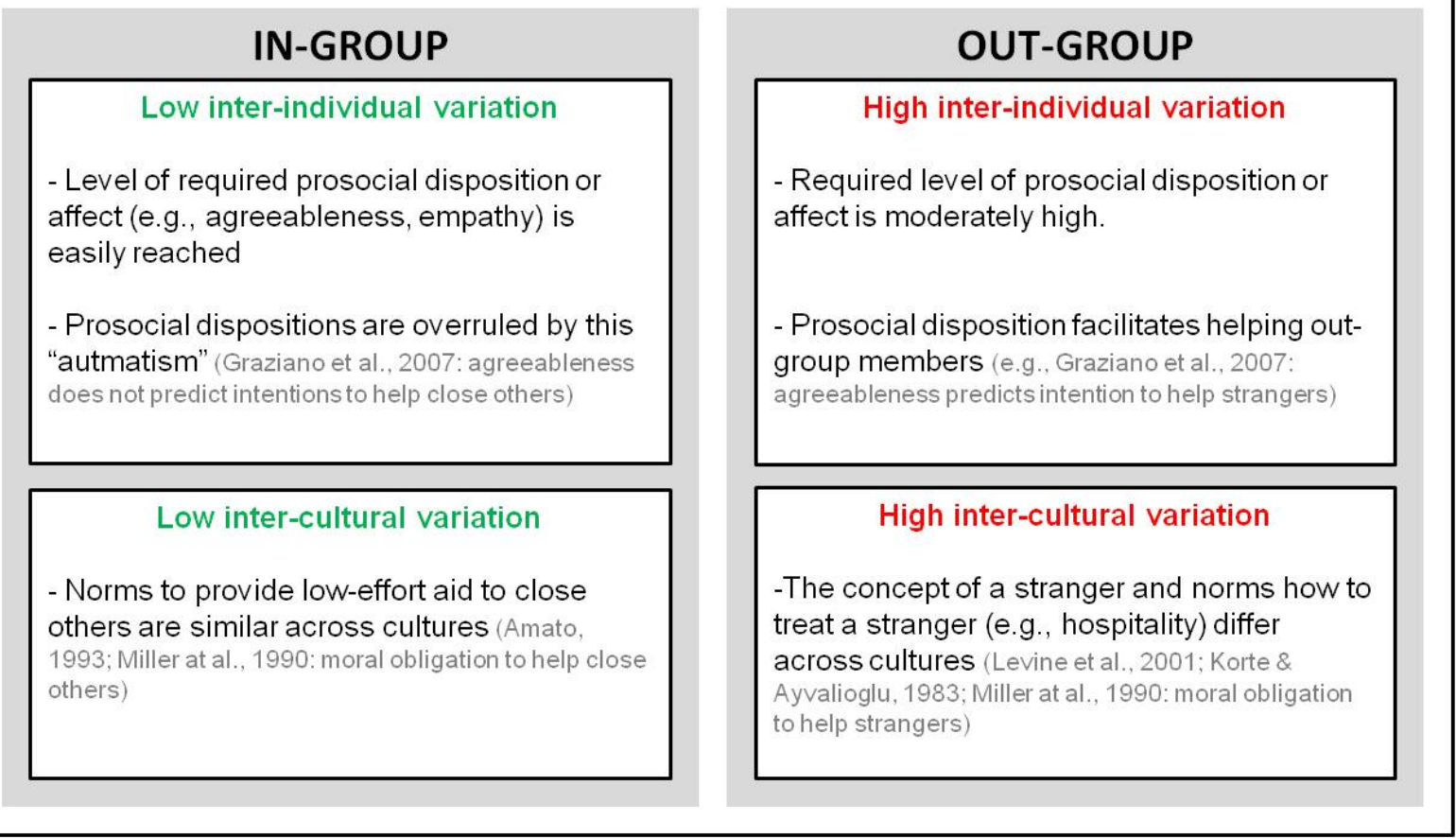

Figure 1. Findings on the likelihood to help spontaneously as a result of target characteristics (in-group/out-group) - implications for individual and cultural differences

individuals holding an individual identification are more likely to engage in out-group volunteering than those holding collective identification.

However, going beyond solely reporting differences in rates of volunteering, we also aim to explain why these differences between different cultural groups occur. We already pointed out that contrary to low effort spontaneous help, we assume volunteering to be a form of helping that is cognition-driven and based on future considerations of reciprocity. . We claim that particularly when helping goes beyond supporting kin or close others, it should comprise elaborations on whether being helped by the target of help in future situations is likely or not, and this should be even more the case when the costs or efforts of helping are high. Notably, considerations of reciprocity do not necessarily need to be consciously accessible to the individual. As shown for instance in Stürmer et al. (2005), the proximate psychological process of interpersonal attraction can serve as a proxy to estimate the probability for future interactions, and thus for reciprocity. 
We apply this reasoning to country-level differences in volunteering. Volunteering is predominantly a form of out-group helping that involves high amounts of effort. Like spontaneous helping, volunteering is affected by socialization goals. However, while situations of spontaneous helping (e.g., holding the door open to someone) mostly require immediate action and do not require and allow for long and extensive considerations, volunteering is a cost-intensive and far-reaching activity that is unlikely to be performed without prior deliberation. Due to the high costs involved in volunteering, anticipations of future reciprocity gain more influence, even when they are not consciously considered and realized. Accordingly, an important aspect that might be needed to perform helping that is high in cost and directed at strangers could be interpersonal trust, since it increases the belief in the probability of future reciprocity.

Empirical support for the assumption that trust is a prerequisite to perform high effort formal helping comes from Allik and Realo (2004). They showed a positive relationship between generalized trust and civic engagement across 42 countries. The higher the scores on trust, the higher were also the rates for civic engagement. Furthermore, and in line with previous findings, Allik and Realo also showed that scores on both variables trust and civic engagement- were typically higher in countries characterized as individualistic.

This can be explained by applying Triandis' (1991) argument that "individualists are more likely than collectivists to trust people they do not know, strangers, and outsiders" (p.81) and hence also more likely to provide cost-intensive help to strangers. To interpret their findings, Allik and Realo (2004) further apply the perspective of Durkheim (1984) and draw attention to the argument that

"when individuals become more autonomous and seemingly liberated from social bonds, they actually become even more dependent on society" (Allik \& Realo, 2004, p.29).

Again, this highlights the reciprocal nature of helping and underlines the importance of considering ontogenetic differences in explaining the psychological adaptiveness of prosocial activities (see also Kaertner, Keller \& Chaudhary, 2010). Our interpretation is compatible with the argument that the presence of voluntary organizations, and hence opportunity to volunteer, differs across societies, and may ultimately lead to the observed differences in rates of volunteering. Certainly, individuals in not industrialized and poor contexts might be less likely to engage in volunteering as the needed structures are missing, or as they are less confronted with opportunities to volunteer. Yet, we should ask why in some contexts it is apparently more likely to meet established structures, whereas in other contexts it is not. We suggest that in modern, western societies these organizations somehow substitute the intergenerational contracts of traditional and poor societies as they largely equal with respect to their adaptive function (Putnam, 2000). An illustrative summary of the processes involved in long-term or repeated planned helping, including volunteering is given in Figure 2. 


\section{PLANNED HELPING: \\ CONSCIOUS CONSIDERATE PATHWAYS}

High amount of effort/costs

High relevance of reciprocity/trust

High threshold to provide help

\section{IN-GROUP (mostly informal)}

Low to moderate inter-individual variation

- Cost-intensive helping more likely when target emotionally close (Fineman et al., 1996)

- Levels of emotional closeness and empathy towards in-aroup members unlikely to vary

Low to moderate inter-cultural variation

- No urban rural differences in helping when help is directed close others (Amato 1993)

-Emotional closeness similar across cultures (Georaas et al., 2006)

- Stronger intergenerational (in-aroup) dependencies in traditional societies

(Kaăutcıbası, 1997, 2007)

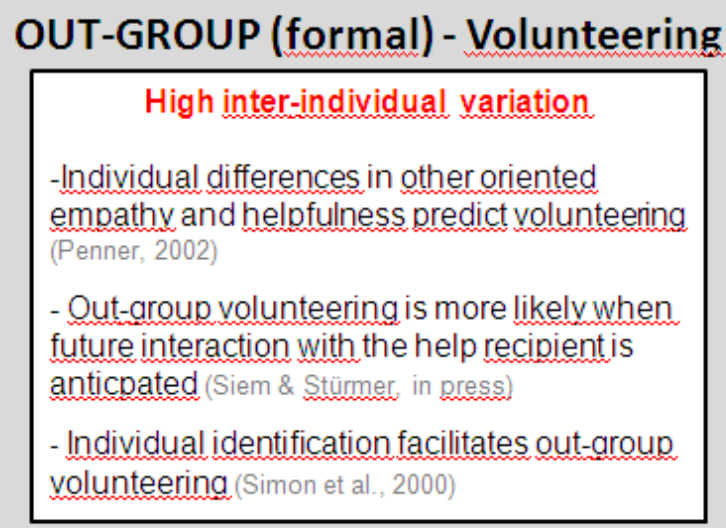

High inter-cultural variation

-Trust significantly relates to civic engagement (Allik \& Realo, 2004)

- Individualists more likely to trust strangers than collectivists (Triandis, 1991)

- Stronger societal (out-aroup) dependencies in modern societies (Durkheim, 1984; Kaăutclbas, 1997, 2007)

Figure 2: Findings on the likelihood to provide planned helping as a result of target characteristics (in-group/out-group) - implications for individual and cultural differences.

\section{Future Directions}

This review demonstrates that investigating cultural effects on helping is a progressing, yet incomplete area of research. We reported findings on spontaneous help and volunteering of studies that mainly compared these two forms prosocial acting on country-level. However, investigations on data obtained and interpreted at the individual level are still rare sightings in this research area. Based on the so far reported results, we can hardly derive conclusions with respect to an individuals' tendency to help. While we can summarize that spontaneous help directed at strangers is indeed more likely to occur in less affluent contexts (e.g., Levine et al., 2001), although this does not clarify the relationship between helping and an individuals' own socio-economic status. In other 
words, research on helping is needed that simultaneously considers characteristics of the environment and the individual, and that applies an interactional approach to investigate helping.

It is equally necessary to move beyond using only self-reports in the assessment of prosocial behavior. In some research on helping self-reported intentions to help were used as dependent variable. However, we need to be aware that such self-reports and actual real life behavioral tendencies are often not related. An illustration for this danger comes from Schwartz (1973). His results showed that individuals' self-reported readiness to donate bone marrow was not predictive for how these individuals reacted to a realistic appeal to join a potential pool of donors three months later. Hence, results obtained from studies that are based on self-reported helping or volunteering intentions as a final outcome variable should not unconditionally be used to draw conclusions on real life helping behaviors. Instead, to gain valid conclusions, we need to include real life helping measures more frequently.

Self-reports, not only as a proxy for real life helping, but also as predictors for helping (e.g., self-reported personality traits, motivations) are affected by response tendencies, such as social desirability. None of the studies investigating personal variables related to spontaneous helping or volunteering has used implicit or projective measures as predictors, which are not affected by such response distortions. Instead, all of them solely relied on information that the participant consciously weighed and finally decided to report. Instead, using for instance measures of implicit motivation might allow for more insight.

The implicit motivation to act prosocially is significantly related to various psychological outcomes, such as parenthood (Chasiotis, Hofer \& Campos, 2006) or generativity (Hofer, Busch, Chasiotis, Kaertner \& Campos, 2008). Similarly, it could also be related to helping since implicit motives -that represent the unconscious part of one's motivational system- are generally predictive for spontaneous behaviors (McClelland, Koestner \& Weinberger, 1989), and moreover determine the kind of activities from which a person derives positive affect (Schultheiss, 2008).

Explicit (or self-reported) motives on the other hand operate on a conscious cognitive level, and are rather predictive for behaviors that are consciously planned (McClelland et al., 1989).

We therefore propose that implicit (unconscious) prosocial motivation may be more related to spontaneous and informal forms of helping, whereas explicit (conscious) prosocial motivation may be more related to more planned and formal forms of helping. This argument is also in line with the reported findings for spontaneous help vs. volunteering and the proposed two-process model of helping.

First empirical support for the validity of these relationships comes from a study conducted by Aydinli, Bender, Chasiotis, van de Vijver and Cemalcilar (2012a). In this study we collected data from 700 adults in the Netherlands by means of a large panel (LISSpanel; http://www.lissdata.nl/lissdata/), and assessed participants' implicit prosocial motivation and their self-reported level of agreeableness. Participants were then presented with a list of 8 prosocial behaviors, asking for the willingness to perform informal and short- 
term helping (6 items) and long-term and formal helping, namely volunteering (2 items). Three main findings were obtained by this study.

1) For volunteering, a significant main effect of self-reported agreeableness was found, meaning that the higher someone scored on agreeableness the higher were also the scores on willingness to volunteer.

2) For informal and short term helping, both agreeableness and implicit prosocial motivation showed a significant main effect. The higher agreeableness and also the higher implicit prosocial motivation, the higher was the willingness to perform informal helping. Hence, and as proposed in our model, more implicit and unconscious mechanisms seem to be involved in initiating low-effort and short-term forms of helping.

3) A significant interaction effect of agreeableness and implicit prosocial motivation for informal helping emerged. Even when scores on self-reported agreeableness were low, implicit prosocial motivation was sufficient to predict informal helping. More specifically, this means that implicit measures explain variance in spontaneous helping that go beyond the predictive effect of self-reports only. Overall, the findings of Aydinli et al. (2012a) indicate that implicit prosocial motivation bestrides the effect of agreeableness and is sufficiently powerful to predict informal and short-term helping.

A next step in research for gaining further insight into the processes involved into helping, Aydinli and colleagues (Aydinli, Bender, Chasiotis, van de Vijver \& Cemalcilar, 2012b) are currently testing whether the same relationships hold true with real-life helping behavior as dependent variable. In line with the suggestion of this article, they address cultural effects on helping, and test whether similar relationships can be found in different cultural settings in order to find out whether the processes initiating different forms of helping are similar across different cultural groups.

\section{Conclusion}

We set out to investigate what the reasons are that prompt people to engage in spontaneous helping and volunteering and whether these reasons are similar across cultural groups. Based on the reviewed literature we conclude that spontaneous helping is initiated via unconscious and affect-based pathways, whereas volunteering seems to be initiated by more rational and conscious cost-benefit evaluations involving trust and reciprocity. We further propose that the two pathways leading to different forms of helping are likely to be similar across different cultural groups.

However, the reviewed studies also illustrated that differences in helping frequencies

exist, particularly when the beneficent is an out-group member: Spontaneous helping towards a stranger is more likely to be performed in traditional and poorer contexts (e.g., Korte \& Kerr, 1975; Levine et al., 2001; Miller et al., 1990), whereas the opposite is the 
case for volunteering (e.g., Curtis et al., 2001; Allik \& Realo, 2004; Kemmelmeier et al., 2006).

We assume that this difference can largely be explained by considering the psychological adaptiveness of antecedents of helping which originate during early ontogeny (Chasiotis, 2011b). The formation of those antecedents in turn is shaped by contextual factors that largely differ across cultures (Kagitcibasi, 1997, 2007). An inclusion of such factors, including childhood contextual variables like number of siblings (Bender \& Chasiotis, 2011: Chasiotis et al., 2006) and parental SES (Chasiotis, Bender \& Hofer, in press), will help provide a better understanding of the psychological mechanics of helping across cultures. We furthermore believe that moving beyond self-reports will open new avenues to research on helping.

The consideration of implicit prosocial motivation will enable us to gain a deeper insight to the research field, and might even help to explain some of the cultural variance in helping. Previous research has shown that we can combine motivation and development: differences in family and childhood context between cultural groups may lead to different compositions of implicit motivations (e.g., Chasiotis et al., 2006; for a recent overview see Hofer \& Chasiotis, 2011) and ultimately to differences in helping tendencies between different societies.

\section{References}

Allik, J., \& Realo, A. (2004). Individualism-collectivism and social capital. Journal of CrossCultural Psychology, 35, 29-49. http://dx.doi.org/10.1177/0022022103260381

Amato, P. R. (1993). Urban-Rural Differences in Helping Friends and Family Members. Social Psychology Quarterly, 56, 249-262. http://dx.doi.org/10.2307/2786662

Atkins, R., Hart, D., \& Donnelly, T. (2005). The association of childhood personality type with volunteering during adolescence. Merrill-Palmer Quarterly, 51, 145-162. http://dx.doi.org/10.1353/mpq.2005.0008

Aydinli, A., Bender, M., Chasiotis, A., van de Vijver, F.J.R., \& Cemalcilar, Z. (2012a). Determinants of prosocial behavior: Formal helping is based on agreeableness, informal helping on implicit prosocial motivation. Manuscript submitted for publication.

Aydinli, A., Bender, M., Chasiotis, A., van de Vijver, F.J.R., \& Cemalcilar, Z. (2012b). Effects of prosocial power on helping: Cross-cultural evidence. Manuscript in preparation.

Barrett, L., Dunbar, R., \& Lycett, J. (2002). Human Evolutionary Psychology. Princeton, NJ: Princeton Univ. Press.

Batson, C. D., Ahmad, N., Lishner, D. A., \& Tsang, J. (2002). Empathy and altruism. In C. R. Snyder, \& S. L. Lopez (Eds.), Handbook of positive psychology (pp. 485- 498). New York: Oxford University Press. 
Batson, C. D., \& Shaw, L. L. (1991). Evidence for altruism: Toward a pluralism of prosocial motives. Psychological Inquiry, 2, 107-122. http://dx.doi.org/10.1207/s15327965 pli0202 1

Bender, M., \& Chasiotis, A. (2011). Number of siblings in childhood explains cultural variance in autobiographical memory in Cameroon, PR China, and Germany. Journal of Cross-Cultural Psychology, 42, 998-1017. http://dx.doi.org/10.1177/ $\underline{0022022110381127}$

Bronfenbrenner, U. (1979). The ecology of human development. Cambridge, MA: Harvard University Press.

Burnstein, E., Crandall, C., \& Kitayama, S. (1994). Some neo-Darwinian decision rules for altruism: weighing cues for inclusive fitness as a function of the biological importance of the decision. Journal of Personality and Social Psychology, 67, 773-789. http://dx.doi.org/10.1037/0022-3514.67.5.773

Caprara, G. V., Alessandri, G., Di Giunta, L., Panerai, L., \& Eisenberg, N. (2010). The contribution of agreeableness and self-efficacy beliefs to prosociality. European Journal of Personality, 24, 36-55. http://dx.doi.org/10.1002/per.739

Caprara, G. V., Alessandri, G., \& Eisenberg, N. (2012). Prosociality: The contribution of traits, values, and self-efficacy beliefs. Journal of Personality and Social Psychology, 102, 1289-1303. http://dx.doi.org/10.1037/a0025626

Cemalcilar, Z. (2009). Understanding individual characteristics of adolescents who volunteer. Personality and Individual Differences, 46, 432-436. http://dx.doi.org/ 10.1016/i.paid.2008.11.009

Chasiotis, A. (2011a). Evolution and culture. Online Readings in Psychology and Culture, Unit 9. Retrieved from http://scholarworks.gvsu.edu/orpc/vol9/iss1/1

Chasiotis, A. (2011b). An epigenetic view on culture: What evolutionary developmental psychology has to offer for cross-cultural psychology. In F. J. R. van de Vijver, A. Chasiotis, \& S. M. Breugelmans (Eds.), Fundamental questions in Cross-Cultural Psychology (pp. 376-404). Cambridge: Cambridge University Press.

Chasiotis, A., Bender, M., \& Hofer, J. (in press). Childhood context explains cultural variance in implicit parenting motivation: Results from two studies with six samples from Cameroon, Costa Rica, Germany, and PR China. Evolutionary Psychology.

Chasiotis, A., Hofer, J., \& Campos, D. (2006). When does liking children lead to parenthood? Younger siblings, implicit prosocial power motivation, and explicit love for children predict parenthood across cultures. Journal of Cultural and Evolutionary Psychology, 4, 95-123. http://dx.doi.org/10.1556/JCEP.4.2006.2.2

Clary, E. G., Snyder, M., Ridge, R. D., Copeland, J., Stukas, A. A., Haugen, J., \& Miene, P. (1998). Understanding and assessing the motivations of volunteers: A functional approach. Journal of Personality and Social Psychology, 74, 1516-1530. http://dx.doi.org/10.1037//0022-3514.74.6.1516

Curtis, J. E. (1971). Voluntary association joining: A cross-national comparative note. American Journal of Sociology, 36, 872-80. http://dx.doi.org/10.2307/2093673 
Curtis, J. E., Grabb, E. G., \& Baer, D. E. (1992). Voluntary association memberships in fifteen countries. American Journal of Sociology 57,139-52. http://dx.doi.org/ $\underline{10.2307 / 2096201}$

Curtis, J. E., Baer, D. \& Grabb, E. G. (2001). Nations of joiners: Explaining voluntary association membership in democratic societies. American Sociological Review, 66, 783-805. http://dx.doi.org/10.2307/3088873

Díaz-Loving, R., \& Draguns, J. G. (1999). Culture, meaning, and personality in Mexico and in the United States. In Y. T. Lee, C. R. McCauley, \& J. G. Draguns (Eds.), Personality and person perception across cultures (pp. 103-126). Mahwah, NJ: Erlbaum.

Dunn, E. W., Aknin, L. B., \& Norton, M. I. (2008). Spending money on others promotes happiness. Science, 319, 1687-1688. http://dx.doi.org/10.1126/science.1150952

Durkheim, E. (1984). The division of labor in society. London, UK: MacMillan. (Original work published 1893).

Eisenberg, N., \& Fabes, R. A. (1991). Prosocial behavior and empathy: A multimethod development perspective. In M. S. Clark (Ed.), Review of personality and social psychology: Prosocial behavior (pp. 34 -61). Newbury Park, CA: Sage.

Eisenberg, N., Fabes, R.A., \& Spinrad, T. L. (2006). Prosocial development. In W. Damon, \& R. Lerner (Eds.), Handbook of child psychology: Social, emotional, and personality development (pp. 647-702). Hoboken, NJ: John Wiley \& Sons.

Fijneman, Y. A., Willemsen, M. E., \& Poortinga, Y. H. (1996). Individualism-Collectivism: An empirical study of a conceptual issue. Journal of Cross-Cultural Psychology, 27, 381-402. http://dx.doi.org/10.1177/0022022196274001

Foa, U. G., \& Foa, E. B. (1975). Resource theory of social exchange. Morristown, NJ: General Learning Press.

Fultz, J., Schaller, M., \& Cialdini, R. B. (1988). Empathy, sadness, and distress: Three related but distinct vicarious affective responses to another's suffering. Personality and Social Psychology Bulletin, 14, 312-325. http://dx.doi.org/10.1177/0146167288 142009

Georgas, J., Berry, J. W., van de Vijver, F. J. R., Kagitcibasi, C., Poortinga Y. H. (2006). Families across cultures: A 30-nation psychological study. Cambridge, UK: Cambridge University Press.

Graziano, W. G., Habashi, M. M., Sheese, B. E., \& Tobin, R. M. (2007). Agreeableness, empathy, and helping: A person $\times$ situation perspective. Journal of Personality and Social Psychology, 93, 583-599. http://dx.doi.org/10.1037/0022-3514.93.4.583

Hamilton, W. D. (1964). The genetical evolution of social behavious. Journal of Theoretical Biology, 7, 1-52. http://dx.doi.org/10.1016/0022-5193(64)90039-6

Hofer, J., Busch, H., Chasiotis, A., Kärtner, J., \& Campos, D. (2008). Concern for generativity and its relation to implicit power motivation, generative goals, and satisfaction with life: A cross-cultural investigation. Journal of Personality, 76, 1-30. http://dx.doi.org/10.1111/j.1467-6494.2007.00478.x 
Hofer, J., \& Chasiotis, A. (2011). Implicit motives across cultures. Online Readings in Psychology and Culture, Unit 4. Retrieved from http://scholarworks.gvsu.edu/orpc/ $\underline{\mathrm{vol} 4 / \mathrm{iss} 1 / 5}$

House, J., \& Wolf, S. (1978). Effects of urban residence on interpersonal trust and helping behavior. Journal of Personality and Social Psychology, 36, 1029-1043. http://dx.doi.org/10.1037/0022-3514.36.9.1029

Kagitcibasi, C. (1997). Individualism and collectivism. In J. W. Berry, M. H. Segall, \& C. Kagitcibasi (Eds.), Handbook of cross-cultural psychology: Vol. 3. Social behavior and applications (pp. 1-49). Boston, MA: Allyn and Bacon.

Kagitcibasi, C. (2007). Family, self, and human development across cultures: Theories and applications. Mahwah, NJ: Lawrence Erlbaum.

Kaertner, J., Keller, H., \& Chaudhary, N. (2010). Cognitive and social influences on early prosocial behavior in two sociocultural contexts. Developmental Psychology, 46, 905-914. http://dx.doi.org/10.1037/a0019718

Kemmelmeier, M., Jambor, E. E., \& Leitner, J. (2006). Individualism and good works: Cultural variation in giving and volunteering across the United States. Journal of Cross-Cultural Psychology 37, 327-344. http://dx.doi.org/10.1177/0022022106 286927

Korte , C., \& Ayvalioglu , N. (1981). Helpfulness in Turkey: Cities, towns, and urban villagers. Journal of Cross-Cultural Psychology, 12, 123-131. http://dx.doi.org/ $10.1177 / 0022022181122001$

Korte, C., \& Kerr, N. (1975). Response to altruistic opportunities in urban and non-urban settings. The Journal of Social Psychology, 95, 183-184. http://dx.doi.org/10.1080/ 00224545.1975 .9918701

Levine, R. V. (2003). Measuring helping behavior across cultures. Online Readings in Psychology and Culture, Unit 5. Retrieved from http://scholarworks.gvsu.edu/orpc/ vol5/iss3/2

Levine, R. V., Norenzayan, A., \& Philbrick, K. (2001). Cross-cultural differences in helping strangers. Journal of Cross-Cultural Psychology, 32, 543-560. http://dx.doi.org/ 10.1177/0022022101032005002

Lindsey, L. L. M., Yun, K. A., \& Hill, J. B. (2007). Anticipated guilt as motivation to help unknown others: An examination of empathy as a moderator. Communication Research, 34, 468-480. http://dx.doi.org/10.1177/0093650207302789

McClelland, D. C., Koestner, R., \& Weinberger, J. (1989). How do self-attributed and implicit motives differ? Psychological Review, 96, 690-702. http://dx.doi.org/ 10.1037/0033-295x.96.4.690

McFarland, S., Webb, M., \& Brown, D. (2012) All humanity is my ingroup: A measure and studies of identification with all humanity. Journal of Personality and Social Psychology, 103, 830-853. http://dx.doi.org/10.1037/a0028724

McGuire, A. M. (1994). Helping behaviors in the natural environment: Dimensions and correlates of helping. Personality and Social Psychology Bulletin, 20, 45-56. http://dx.doi.org/ 10.1177/0146167294201004 
Mendoza-Denton, R., Ayduk, O., Mischel, W., Shoda, Y., \& Testa, A. (2001). Person × Situation interactionism in self-encoding (I am...when...): Implications for affect regulation and social information processing. Journal of Personality and Social Psychology, 80, 533-544. http://dx.doi.org/10.1037/0022-3514.80.4.533

Miller, J. G., Bersoff, D. M., \& Harwood, R. L. (1990). Perceptions of social responsibilities in India and in the United States: Moral imperatives or personal decisions? Journal of Personality and Social Psychology, 58, 33-47. http://dx.doi.org/10.1037/0022$\underline{3514.58 .1 .33}$

Mischel, W., \& Shoda, Y. (1995). A cognitive-affective system theory of personality: Reconceptualizing situations, dispositions, dynamics, and invariance in personality structure. Psychological Review, 102, 246-268. http://dx.doi.org/10.1037/0033295X.102.2.246

Omoto, A. M. \& Snyder, M. (1995). Sustained helping without obligation: Motivation, longevity of service, and perceived attitude change among AIDS volunteers. Journal of Personality and Social Psychology, 68, 671-686. http://dx.doi.org/10.1037/00223514.68.4.671

Pearce, P., \& Amato, P. R. (1980). A taxonomy of helping: A multidimensional scaling approach. Social Psychology Quarterly 43, 363-371. http://dx.doi.org/10.2307/3033956

Penner, L. A. (2002). Dispositional and organizational influences on sustained volunteerism: An interactionist perspective. Journal of Social Issues, 58, 447-468. http://dx.doi.org/10.1111/1540-4560.00270

Penner, L. A., Fritzsche, B. A., Craiger, J. P., \& Freifeld, T. S. (1995). Measuring the prosocial personality. In J. Butcher \& C. D. Spielberger (Eds.), Advances in Personality Assessment (pp. 147-163). Hillsdale, NJ: LEA.

Penner, L. A., \& Finkelstein, M. A. (1998). Dispositional and structural determinants of volunteerism. Journal of Personality and Social Psychology, 74, 525-537. http://dx.doi.org/10.1037/0022-3514.74.2.525

Piliavin, J. A., Dovidio, J. F., Gaertner, S., \& Clark, R. D. (1981). Emergency intervention. New York: Academic Press.

Putnam, R. D. (1995). Bowling alone: America's declining social capital. Journal of Democracy, 6, 65-78. http://dx.doi.org/10.1353/jod.1995.0002

Putnam, R. D. (2000). Bowling alone: The collapse and revival of American community. New York: Simon \& Schuster.

Schaller, M., \& Cialdini, R. B. (1988). The economics of empathic helping: Support for a mood management motive. Journal of Experimental Social Psychology, 24, 163-181. http://dx.doi.org/10.1016/0022-1031(88)90019-4

Schultheiss, O. C. (2008). Implicit motives. In O. P. John, R. W. Robins, \& L. A. Pervin (Eds.), Handbook of Personality: Theory and Research (pp. 603-633). New York: Guilford.

Schwartz, H. S. (1973). Normative explanations of helping behavior: A critique, proposal, and empirical test. Journal of Experimental Social Psychology, 9, 349-364. http://dx.doi.org/10.1016/0022-1031(73)90071-1 
Siem, B., \& Stürmer, S. (in press). Cross-cultural volunteerism: Examining the effects of intercultural (dis)similarities on volunteers' motivations to support international students. Basic and Applied Social Psychology.

Simon, B., Stürmer, S., \& Steffens, K. (2000). Helping individuals or group members? The role of individual and collective identification in AIDS volunteerism. Personality and Social Psychology Bulletin, 26, 497-506. http://dx.doi.org/10.1177/0146167 200266008

Smith, K. D., Keating, J.P., \& Stotland, E. (1989). Altruism reconsidered: The effect of denying feedback on a victim's status to empathic witnesses. Journal of Personality and Social Psychology, 57, 641-650. http://dx.doi.org/10.1037/0022-3514.57.4.641

Stürmer, S, \& Simon, B. (2004). The role of collective identification in social movement participation: A panel study in the context of the German gay movement. Personality and Social Psychology Bulletin, 30, 263-277. http://dx.doi.org/10.1177/ 0146167203256690

Stürmer, S., \& Snyder, M. (2010). Helping 'us' versus 'them': Towards a group-level theory of helping and altruism within and across group boundaries. In S. Stürmer, \& M. Snyder (Eds.), The psychology of prosocial behavior: Group processes, intergroup relations, and helping (pp.33-58). Oxford, UK: Wiley-Blackwell.

Stürmer, S., Snyder, M., Kropp, A., \& Siem, B. (2006). Empathy-motivated helping: The moderating role of group membership. Personality and Social Psychology Bulletin, 32, 943-956. http://dx.doi.org/10.1177/0146167206287363

Stürmer, S., \& Snyder, M., \& Omoto, A. M. (2005). Prosocial emotions and helping: The moderating role of group membership. Journal of Personality and Social Psychology, 88, 532-546. http://dx.doi.org/10.1037/0022-3514.88.3.532

Triandis, H. C. (1991). Cross-cultural differences in assertiveness/competition vs. group loyalty/cooperation. In R. A. Hinde, \& J. Groebel (Ed), Cooperation and prosocial behavior (pp. 78-88). New York: Cambridge University Press.

Triandis, H. C. (1995). Individualism and collectivism. Boulder, CO: Westview.

Triandis, H. C., Marín, G., Lisansky, J., \& Betancourt, H. (1984). Simpatía as a cultural script of Hispanics. Journal of Personality and Social Psychology, 47, 1363-1375. http://dx.doi.org/10.1037/0022-3514.47.6.1363

Trivers, R. L. (1971). The evolution of reciprocal altruism. Quartely Review of Biology, 46, 35-57. http://dx.doi.org/10.1086/406755

Twenge, J. M., Baumeister, R. F., DeWall, C. N., Ciarocco, N. J., \& Bartels, J. M. (2007). Social exclusion decreases prosocial behavior. Journal of Personality and Social Psychology, 92, 56-66. http://dx.doi.org/10.1037/0022-3514.92.1.56

Wilson, J. (2000). Volunteering. Annual Review of Sociology, 26, 215-240. http://dx.doi.org/10.1146/annurev.soc.26.1.215 


\section{About the authors}

Arzu Aydinli (1983) is a PhD candidate at the Department of Cross-Cultural Psychology at Tilburg University, the Netherlands. She graduated in psychology from the University of Tübingen, Germany, where she had worked on mood effects on persuasive information processing. Her current research concentrates on motives and prosocial behavior from a cross-cultural perspective.

Michael Bender (1978) is Assistant Professor at the Department of Cross-Cultural Psychology at Tilburg University, the Netherlands. He has previously worked at Barnard College, Columbia University, New York, USA, at the City University of Hong Kong, PR China and the University of Osnabrück, Germany, where he received his PhD. His work focuses on motivation and memory, from a cross-cultural and developmental perspective. $\mathrm{He}$ is associate editor of the Online Readings in Psychology and Culture, and has published in such journals as the Journal of Cross-Cultural Psychology, the Journal of Research in Personality, and Applied Cognitive Psychology.

Athanasios Chasiotis (1964) is Associate Professor in Cross-Cultural Psychology at Tilburg University, the Netherlands. He published in the fields of Cross-cultural, Developmental, Evolutionary, and Personality Psychology, in Behavioural Ecology and in Evolutionary Anthropology. He is Co-editor of Grandmotherhood - The evolutionary significance of the second half of female life (2005, Rutgers University Press) and of Fundamental Questions in Cross-cultural Psychology (2011, Cambridge University Press), and Co-author of the textbook Cross-cultural Psychology - Research and Applications (2011, 3rd ed., Cambridge University Press).

\section{Suggestions for further reading}

Hofer, J., \& Chasiotis, A. (2011). Implicit motives across cultures. Online Readings in Psychology and Culture, Unit 4. Retrieved from http://scholarworks.gvsu.edu/orpc/ vol4/iss $1 / 5$

Penner, L. A., Dovidio, J. F., Schroeder, D. A., \& Piliavin, J. A. (2005). Prosocial behavior: Multilevel perspectives. Annual Review of Psychology, 56, 365-392. http://dx.doi.org/10.1146/annurev.psych.56.091103.070141

Schultheiss, O. C., \& Brunstein, J. C. (2010). Implicit motives. New York: Oxford University Press.

Stürmer, S., \& Snyder, M. (2010). The psychology of prosocial behavior: Group processes, intergroup relations, and helping. Oxford, UK: Wiley-Blackwell.

Wilson, J. (2012). Volunteerism research: A review essay. Nonprofit and Voluntary Sector Quaterly, 41, 176-212. http://dx.doi.org/10.1177/0899764011434558 


\section{Discussion questions}

1) Recall examples of spontaneous helping and volunteering that occurred to you and discuss whether and to what extent the reasons and antecedents for engaging in these two forms of helping were similar or different in your case.

2) On which dimensions do spontaneous helping and volunteering differ, and what kind of implications do these differences have for the way how the respective forms of helping are realized?

3) Come up with examples of situational or contextual variables that might influence an individuals' inclination to engage in both spontaneous helping and voluntary work.

4) Discuss how and to what extent the target of helping affects the processes initiating both short-term spontaneous helping and long-term planned helping (including volunteering).

5) How can it be explained that spontaneous helping directed at strangers is more frequent in poorer contexts, whereas volunteering is more frequent in affluent contexts?

6) What are the main problems in current psychological research on helping, and how can they be addressed in future research?

7) How could the proposed two processes of helping be translated into cross-cultural studies? Propose a concrete study design that tests the expected relationships. 